\title{
Corrigendum: Platelet Counts and Patent Ductus Arteriosus in Preterm Infants: An Updated Systematic Review and Meta-Analysis
}

\author{
Gema González-Luis ${ }^{1}$, Stefano Ghirardello ${ }^{2}$, Pilar Bas-Suárez ${ }^{3}$, Giacomo Cavallaro ${ }^{2}$, \\ Fabio Mosca ${ }^{2,4}$, Ronald I. Clyman ${ }^{5}$ and Eduardo Villamor ${ }^{6 *}$
}

${ }^{1}$ Department of Neonatology, Complejo Hospitalario Universitario Insular Materno-Infantil (CHUIMI) de Canarias, Las Palmas de Gran Canaria, Spain, ${ }^{2}$ Neonatal Intensive Care Unit, Fondazione IRCCS Ca' Granda Ospedale Maggiore Policlinico, Milan, Italy, ${ }^{3}$ Department of Pediatrics, Hospital Vithas Santa Catalina, Las Palmas de Gran Canaria, Spain, ${ }^{4}$ Department of Clinical Sciences and Community Health, Università degli Studi di Milano, Milan, Italy, ${ }^{5}$ Cardiovascular Research Institute, Department of Pediatrics, University of California, San Francisco, San Francisco, CA, United States, ${ }^{6}$ Department of Pediatrics, Maastricht University Medical Center (MUMC+), School for Oncology and Developmental Biology (GROW), Maastricht, Netherlands

Keywords: ductus arteriosus, platelets, meta-analysis, platelet distribution width, thrombocytopenia

\section{OPEN ACCESS}

Edited and reviewed by: Arjan Te Pas,

Leiden University, Netherlands

*Correspondence: Eduardo Villamor e.villamor@mumc.nı

Specialty section: This article was submitted to Neonatology, a section of the journal Frontiers in Pediatrics

Received: 13 April 2021 Accepted: 22 April 2021 Published: 19 May 2021

Citation:

González-Luis G, Ghirardello S, Bas-Suárez P, Cavallaro G, Mosca F, Clyman RI and Villamor E (2021)

Corrigendum: Platelet Counts and Patent Ductus Arteriosus in Preterm Infants: An Updated Systematic

Review and Meta-Analysis.

Front. Pediatr. 9:694606.

doi: 10.3389/fped.2021.694606

\section{A Corrigendum on}

Platelet Counts and Patent Ductus Arteriosus in Preterm Infants: An Updated Systematic Review and Meta-Analysis

by González-Luis, G., Ghirardello, S., Bas-Suárez, P., Cavallaro, G., Mosca, F., Clyman, R. I., et al. (2021). Front. Pediatr. 8:613766. doi: 10.3389/fped.2020.613766

An author name was incorrectly spelled as Stefano Ghiradello. The correct spelling is Stefano Ghirardello.

In the published article, there was an error in affiliation 2. Instead of "Neonatal Intensive Care Unit, Department of Clinical Sciences and Community Health, Fondazione IRCCS Cà Granda Ospedale Maggiore Policlinico, Università degli Studi di Milano, Milan, Italy.", it should be "Neonatal Intensive Care Unit, Fondazione IRCCS Ca' Granda Ospedale Maggiore Policlinico, Milan, Italy."

In the published article, there was an error regarding the affiliation for Fabio Mosca. As well as having affiliation 2, they should also have Department of Clinical Sciences and Community Health, Università degli Studi di Milano, Milan, Italy.

The authors apologize for this error and state that this does not change the scientific conclusions of the article in any way. The original article has been updated.

Copyright (๔ 2021 González-Luis, Ghirardello, Bas-Suárez, Cavallaro, Mosca, Clyman and Villamor. This is an open-access article distributed under the terms of the Creative Commons Attribution License (CC BY). The use, distribution or reproduction in other forums is permitted, provided the original author(s) and the copyright owner(s) are credited and that the original publication in this journal is cited, in accordance with accepted academic practice. No use, distribution or reproduction is permitted which does not comply with these terms. 